\title{
Acute effects of unilateral sectioning the superior ovarian nerve of rats with unilateral ovariectomy on ovarian hormones (progesterone, testosterone and estradiol) levels vary during the estrous cycle
}

Angélica Flores, Jacqueline Velasco, Alma I Gallegos, Fernando D Mendoza, Pamela M Everardo, María-Esther Cruz, Roberto Domínguez*

\begin{abstract}
The present study analyzed the participation of the left and right superior ovarian nerves (SON) in regulating progesterone, testosterone, and estradiol serum levels in unilaterally ovariectomized rats on each day of the estrous cycle. For this purpose, ovarian hormone concentrations in serum were measured in animals with either shamsurgery, unilateral ovariectomy (ULO), unilateral sectioning of the SON, or sectioning of the SON innervation of the in situ ovary in rats with ULO.

This investigation results show that the right and left ovaries have different capacities to maintain normal hormone levels, that such capacity varies during the estrous cycle, and that it depends on the integrity of the SON innervation. In rats with only one ovary, the effects of ovarian denervation on hormone levels varied according to which ovary remained in situ, the specific hormone, and the day of the estrous cycle when treatment was performed. Present results support the idea that the ovaries send and receive neural information that is processed in the central nervous system and we propose that this information participates in controlling the secretion of gonadotropins related to the regulation of ovarian functions.
\end{abstract}

\section{Background}

Asymmetry in the ovaries' morphology, physiology, and regulatory structures is well established. Evidence suggesting that these asymmetries play an important functional role in regulating gonadal functions, and that the degree of asymmetry between gonads fluctuates along the estrous cycle, has been published [1]. The ovarian innervations play a role in regulating the ovulation process [2-5], in hormone secretion [6,7], and function as neural pathways that participate in modulating hypothalamic and non-hypothalamic centres that regulate the secretion of gonadotropins [1]. Furthermore, it has been proposed that the ovarian innervations modulate the reactivity of different ovarian compartments to gonadotropins effects $[1,8]$.

\footnotetext{
* Correspondence: rdcasala@hotmail.com

Biology of Reproduction Research Unit, FES Zaragoza UNAM, México City,
} México DF, México

(c) 2011 Flores et al; licensee BioMed Central Ltd. This is an Open Access article distributed under the terms of the Creative Commons Attribution License (http://creativecommons.org/licenses/by/2.0), which permits unrestricted use, distribution, and reproduction in any medium, provided the original work is properly cited. two main routes: the superior ovarian nerve $(\mathrm{SON})$, which travels along the suspensory ligament; and the ovarian plexus nerves, which reach the ovary together with the main ovarian vessels [9-11]. Evidence that the ovary also receives vagal innervation has been published [12]. Aside from the classical neurotransmitters (noradrenaline (NA) and acetylcholine), several polypeptide neurotransmitters have been documented in the innervations arriving and leaving the ovaries [13-19].

According to Uchida et al [20], neural reflexes from the abdominal skin to the ovaries affect ovarian blood flow and the activity of the SON. The response level depended on whether the left or right abdominal afferent was stimulated, since stimulating the left abdomen produced a much stronger effect on the activity of the left ovarian sympathetic nerve than stimulating the right abdomen. The response of ovarian blood flow to abdominal stimulation is mediated as a reflex response 
via the ovarian sympathetic nerves, and the response is controlled via supra-spinal pathways and depends on the estrous cycle [21].

Niswender et al. [22] suggest that there are evidence indicating that ovarian blood flow is an important factor regulating the activity of gonadotropic hormones at the luteal cell level, and a secondary mechanism of action of LH may be to increase blood flow to the corpus luteum.

Ovarian and uterine arteries with anastomosis between them, provide arterial blood supply to the ovaries. Blood flow to the ovaries varies in magnitude and distribution throughout the estrous cycle [23-25], and the number and distribution of the follicular and luteal capillaries changes throughout the estrous cycle [26].

Most neurones originating from the SON fibers are located in the complex celiac-mesenteric ganglia (CSMG). The SON carries most of the catecholaminergic fibers innervating endocrine ovarian cells, which are distributed in the peri-follicular theca layer and are closely related to the theca internal cells $[9,27]$. In prepubertal rats, 24 and 72 hrs after unilateral or bilateral sectioning of the SON, the NA levels in the denervated ovary were lower than in untouched (control) and laparotomized animals [28].

Aside from the catecholaminergic innervation, the SON provides vasoactive intestinal peptide (VIP) [29] and nitric oxide (NO) [30] innervations to the ovaries. NO inhibits cytochrome P450 aromatase activity and the secretion of estradiol (E2) by granulosa cells in culture [31]. In vitro studies show that in the rat, the participation of neurotransmitters regulating the secretion of ovarian progesterone (P4) varies along the day of the estrous cycle. In diestrus-1 (D1), neuropeptide Y (NPY), NA and VIP inhibit P4 secretion by the ovaries, while on diestrus-2 (D2) these neurotransmitters stimulate P4 secretion. On D1 and D2, the effects of NA + VIP or NA + NPY on P4 secretion were higher than VIP or NPY alone [23]. In the rat, ovary denervation reduces the synthesis and secretion of $\mathrm{P} 4$ by inhibiting 3-betaHSD activity [32]. In the pig, sectioning of the plexus nerve and the SON led to lower plasma levels of $\mathrm{LH}, \mathrm{P} 4$, androstenedione (A4), testosterone (T), estrone and estradiol-17beta. Further, a significant increase in the immuno-expression of cholesterol side-chain cleavage cytochrome P450 in follicles, as well as a decrease of 3-betaHSD, and in plasma levels of luteinizing hormone (LH), P4, A4, T, estrone and estrogen have been documented [33].

Unilateral ovariectomy (ULO) is a useful tool for studying the mechanisms involved in the asymmetric responses of the ovaries to neuroendocrine regulating signals [34-37]. The difference between the right and left ovaries' capacity to release oocytes seems to be related to the type and degree of the innervations in each gonad [1]. According to Klein and Burden [10], the number of neural fibers received by the right ovary is higher than in the left; while, Toth et al. [38] showed that the left ovary sends more neural information to the central nervous system (CNS) than the right ovary. In addition, the right and left ovaries show different ovulatory responses to surgical denervation, and these responses vary according to the day of the estrous cycle when surgery is performed $[3,39]$.

Ovarian denervation by sectioning the vagus nerve has different effects on normal cyclic rats and ULO rats. In normal cyclic rats sectioning the left vagus nerve resulted in lower ovulation rate than in sham operated animals, while sectioning the right vagus nerve did not modify the ovulation rate. Sectioning the right or left vagus nerves to right-ULO rats (left ovary in-situ) reduces compensatory ovarian hypertrophy. In turn, sectioning the left vagus nerve induced different effects depending on which ovary remained in-situ. Left-side vagotomy performed to right ULO rats (left ovary in-situ) resulted in higher ovulation rates, compensatory ovarian hypertrophy, and number of ova shed; while the same procedure to left ULO rats (right ovary in-situ) resulted in a decrease of the same parameters $[2,3]$. In rats, the electrical stimulation to the ovarian plexus nerve or the SON produces a vasoconstriction of ovarian arterioles and a reduction of ovarian blood flow in rats [33]. The stimulation of the SON resulted in a significantly decrease of E2, while electrical stimulation of the ovarian plexus nerve did not modify it. This suggests that autonomic nerves that reach the ovary via the SON have an inhibitory role in the secretion of ovarian E2 [40].

Sensorial innervations also play a role in regulating ovarian functions. Sensorial denervation induced by capsaicin injection, systemic or into the ovarian bursa, diminished spontaneous ovulation and secretion of $\mathrm{P} 4$ and E2 [4]. Capsaicin treatment to ULO rats affect ovulation and the secretion of ovarian steroids depending on which ovary remained in situ and the day of the cycle when treatment was performed [41,42].

By comparing hormone levels in untouched (control) and ULO rats, this investigation studied the participation of the SON innervation in regulating hormone secretion by the left and right ovaries. The following hypotheses were assessed:

1) Since the innervations arising from the ovaries carry neural signals to the CNS, then, extirpating one ovary will produce acute changes in the neuroendocrine mechanisms regulating hormone secretion by the in situ ovary, and the type and magnitude of these changes would depend on which ovary (left or right) remains in situ as well as on which day of the estrous cycle surgery is performed. 
2) Because the participation degree of the ovarian innervations on the modulation of hormone secretion seems to depend on the day of the estrous cycle, then, the acute effects of unilaterally sectioning the SON on P4, T and E2 serum levels will depend on the day of the cycle when denervation is performed.

3) Since after ULO the CNS no longer receives the neural information arising from the extirpated ovary, then, denervating the in situ ovary of animals with ULO, by sectioning the SON, will result in different hormone secretion changes than those resulting from sectioning the SON of animals with both ovaries in situ.

4) Since the neural regulation of ovarian functions seems to be asymmetric and to vary along the estrous cycle, then the changes in P4, T and E2 levels observed in animals with ULO will depend on the ovary remaining in situ and the day of the estrous cycle when ULO surgery, is performed.

5) Since acute bilateral ovariectomy affects ovarian steroid serum levels in different ways, then the effects of ULO, SON sectioning, and ULO + SON sectioning will differ according to the manipulated organ and the hormone studied.

\section{Methods}

For this investigation, virgin adult female rats (195-225g body weight) of the CIIZ-V strain from our own stock were used. The experiments were performed following the guidelines established by The Mexican Law of Animal Protection Guidelines Treatment. The Committee of the Facultad de Estudios Superiores Zaragoza approved the experimental protocols.

Animals were kept under controlled lighting conditions (lights on from 05:00 to 19:00 h), with free access to food (Purina S.A., Mexico) and tap water. Estrous cycles were monitored by daily vaginal smears; only rats showing at least two consecutive 4-day cycles were used in the experiment.

Rats were randomly allotted to one of the five experimental groups described below. Animals from different experimental groups were treated simultaneously and sacrificed one hour after surgery (14.00-14.15 h). All surgeries were performed in rats under ether anesthesia, using a ventral approach 13.00-13.15 hrs on each day of the estrous cycle. The animals woke up immediately after surgery.

\section{Experimental groups}

The number in parenthesis indicates the number of animals in each group.

\section{Control group_ $(N=40)$}

Non-treated cyclic rats (ten animals on each day of the estrous cycle) were sacrificed between 14:00 and14:15 h on diestrus 1 (D1), diestrus 2 (D2), proestrus (P) or estrous (E).

\section{Sham surgery}

An incision, affecting skin, muscle, and peritoneum, was performed $2 \mathrm{~cm}$ below the sternum [D1 (9), D2 (10), P (10) and E (10)]. The wound was subsequently sealed. No organs were extirpated or handled.

\section{Unilateral ovariectomy (ULO)}

A similar incision to that described for sham-surgery treatment was performed to extirpate the right ovary [D1 (9), D2 (9), P (10) and E (10)] or the left ovary [D1 (9), D2 (9), P (9) and E (9)]; the wound was subsequently sealed.

\section{Unilateral sectioning of the superior ovarian nerve}

A similar incision to that described for sham-surgery treatment was performed; the right [D1 (9), D2 (9), P (9) and E (8)] or left [D1 (10), D2 (10), P (10) and E (9)] ovary was exposed and the SON of the ovary was sectioned, as previously described by Chávez et al. [4]. The wound was subsequently sealed.

\section{Unilateral section of the SON to ULO animals}

The right [D1 (9), D2 (9), P (10) and E (10)] or left ovary [D1 (10), D2 (10), P (10) and E (9)] was extirpated and the SON of the in situ ovary was sectioned immediately after. The wound was subsequently sealed.

Figure 1 shows a summary of the treatments

\section{Autopsy procedures}

Rats were sacrificed by decapitation; the blood of the trunk was collected, allowed to clot at room temperature for 30 minutes, and centrifuged at 3,000 rpm during 15 minutes. Serum was stored at $-20^{\circ} \mathrm{C}$, until P4, T and E2 concentrations were measured.

\section{Hormone assay}

Concentrations of P4, T, and E2 in serum were measured using Radio-Immuno-Assay (RIA); with kits purchased from Diagnostic Products (Los Angeles, CA). Analytical results are expressed in $\mathrm{ng} / \mathrm{ml}(\mathrm{P} 4)$ and $\mathrm{pg} / \mathrm{ml}$

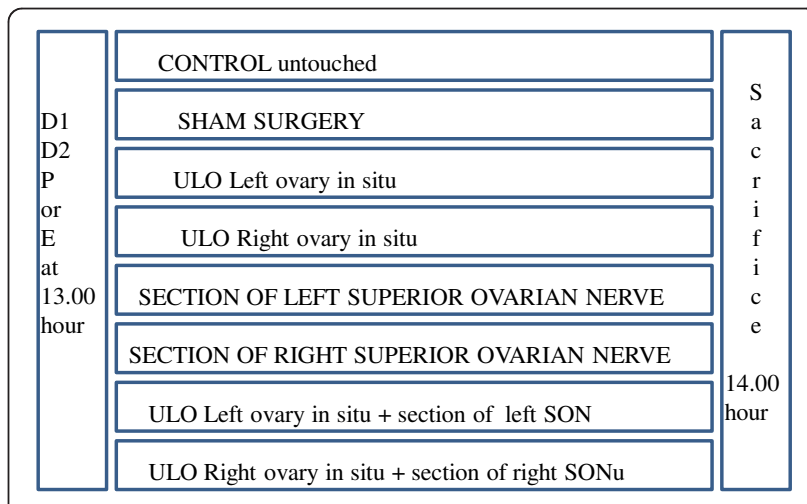

Figure 1 The diagram shows a summary of the treatments ULO = unilateral ovariectomy. D1, D2, P or E = Days of the estrous cycle when surgeries were performed. 
( $\mathrm{T}$ and E2). The intra- and inter-assay percent variation coefficients for P4 were 5.3 and 9.87; for T 5.6 and 8.7 and for E2 6.9 and 10.8, respectively. The detection limits of: P4 $0.05 \mathrm{ng} / \mathrm{ml}$ to $40 \mathrm{ng} / \mathrm{ml}$; correlation coefficient 0.9991 ; T $0.0020 \mathrm{ng} / \mathrm{ml}$ to $8.0 \mathrm{ng} / \mathrm{ml}$, correlation coefficient 0.9851 ; E2 $0.2680 \mathrm{pg} / \mathrm{ml}$ to $900.00 \mathrm{pg} / \mathrm{ml}$; correlation coefficient 0.9960 .

\section{Statistics}

Data on hormonal concentrations in serum were analyzed using multivariate analysis of variance (MANOVA), followed by Turkey's test. Differences in serum hormone concentrations between two groups were analyzed using the Student's t-test. A probability value of less than $5 \%$ was considered significant.

\section{Results}

\section{Effects of sham-surgery (Table 1)}

Compared to the control group, sham surgery on D1, $\mathrm{D} 2$ and $\mathrm{P}$ resulted in higher $\mathrm{P} 4$ concentrations, while sham surgery performed on D2, P or E resulted in higher T concentrations. No changes in E2 serum concentrations were observed. Based on these results, the effects of experimental surgeries were compared to their corresponding sham surgery group.

\section{Effects of ULO (Table 2)}

\section{Effects on P4 serum levels}

Compared to sham-surgery animals, left ULO (right ovary in-situ) did not modify P4 serum levels; regardless of the day treatment was performed. Right ULO (left ovary in-situ) performed on D1 resulted in lower P4 levels, while the same treatment performed on $E$ resulted in higher $\mathrm{P} 4$ concentrations.

\section{Effects on $T$ serum levels}

Compared to sham-surgery animals, left ULO (right ovary in-situ) performed on $\mathrm{P}$ or E resulted in lower T. Compared to sham-surgery animals, right ULO (left ovary in-situ) did not modify hormone serum levels, regardless of the day of the estrous cycle when surgery was performed. Right ULO (left ovary in-situ) on E resulted in higher $\mathrm{T}$ levels than in animals with left ULO (right ovary in situ).

\section{Effects on $E$ serum levels}

Left ULO (right ovary in-situ) on D1 as well as right ULO (left ovary in-situ) on P resulted in lower E2 serum levels. For animals treated on P, right ULO (left ovary in situ) resulted in lower E2 concentrations than in rats with left ULO (right ovary in situ) treatment.

Figure 2 shows a summary of the effects of ULO on $\mathrm{P} 4, \mathrm{~T}$ and $\mathrm{E}$ serum levels

\section{Effects of Sectioning the SON of rats with both ovaries in situ (Table 3)}

Depending on the day of treatment, sectioning the SON of rats with both ovaries in situ had different effects on the concentrations of ovarian hormones in serum.

\section{Effects on P4 serum levels}

Compared to sham-operated animals, sectioning the right SON on D1 or E resulted in higher P4 levels. In rats treated on D2, sectioning the right SON resulted in higher P4 levels than sectioning the left SON; while sectioning the left SON on E resulted in higher P4 levels than sectioning the right SON and in the sham-surgery group.

\section{Effects on $T$ serum levels}

Sectioning the left SON on D1 resulted in higher T levels than sham-surgery or sectioning the right $\mathrm{SON}$ treatment. In turn, sectioning the left SON on D2 resulted in lower $\mathrm{T}$ levels than sham-surgery or sectioning the right SON treatment, while sectioning the right SON on P resulted in lower T levels than sham-surgery or sectioning the left SON treatment.

Regardless of the day surgery was performed, sectioning the left or right SON did not modify E2 concentrations in serum.

Figure 3 shows a summary of the effects of sectioning the SON on $\mathrm{P} 4, \mathrm{~T}$ and $\mathrm{E}$ serum levels

Table 1 Mean \pm SEM of progesterone $(\mathrm{ng} / \mathrm{ml})$, testosterone and estradiol $(\mathrm{pg} / \mathrm{ml})$ serum levels in control and sham treated animals during each day of the estrous cycle

\begin{tabular}{|c|c|c|c|c|c|c|c|c|}
\hline GROUP & $\mathbf{N}$ & D1 & $\mathrm{N}$ & D2 & $\mathrm{N}$ & $P$ & $\mathrm{~N}$ & 0 \\
\hline \multicolumn{9}{|c|}{ PROGESTERONE } \\
\hline Control & 10 & $24.0 \pm 2.8$ & 10 & $7.1 \pm 1.2$ & 10 & $14.1 \pm 2.6$ & 10 & $24.1 \pm 2.4$ \\
\hline Sham & 9 & $63.5 \pm 11.1^{*}$ & 10 & $33.0 \pm 4.4^{*}$ & 10 & $28.7 \pm 2.4^{*}$ & 10 & $26.3 \pm 1.1$ \\
\hline \multicolumn{9}{|c|}{ TESTOSTERONE } \\
\hline Control & 10 & $10.8 \pm 2.0$ & 10 & $73.5 \pm 9.8$ & 10 & $145.8 \pm 18.2$ & 10 & $<2.0$ \\
\hline Sham & 9 & $19.1 \pm 8.6$ & 10 & $103.4 \pm 14.0^{*}$ & 10 & $285.8 \pm 20.8^{*}$ & 10 & $76.5 \pm 20.8^{*}$ \\
\hline \multicolumn{9}{|c|}{ ESTRADIOL } \\
\hline Control & 10 & $59.3 \pm 4.6$ & 10 & $38.9 \pm 2.8$ & 10 & $130.9 \pm 13.1$ & 10 & $29.1 \pm 2.4$ \\
\hline Sham & 9 & $46.6 \pm 5.6$ & 10 & $38.6 \pm 2.8$ & 10 & $149.7 \pm 11.3$ & 10 & $30.2 \pm 2.6$ \\
\hline
\end{tabular}

${ }^{*} \mathrm{p}<0.05$ vs. Control (Student's t test). 
Table 2 Mean \pm SEM of progesterone $(\mathrm{ng} / \mathrm{ml})$, testosterone and estradiol $(\mathrm{pg} / \mathrm{ml})$ serum levels in unilateral ovariectomized rats (ovary in situ)

\begin{tabular}{|c|c|c|c|c|c|c|c|c|}
\hline GROUP & $\mathrm{N}$ & D1 & $\mathrm{N}$ & D2 & $\mathrm{N}$ & $\mathbf{P}$ & $\mathrm{N}$ & 0 \\
\hline \multicolumn{9}{|c|}{ PROGESTERONE } \\
\hline Sham & 9 & $63.5 \pm 11.1$ & 10 & $33.0 \pm 4.4$ & 10 & $28.7 \pm 2.4$ & 10 & $26.3 \pm 1.1$ \\
\hline R-OVARY & 10 & $78.1 \pm 11.6$ & 10 & $38.5 \pm 3.0$ & 10 & $25.8 \pm 2.1$ & 8 & $35.2 \pm 4.0$ \\
\hline L-OVARY & 9 & $39.2 \pm 3.1^{*}$ & 9 & $32.3 \pm 4.3$ & 8 & $28.7 \pm 3.0$ & 10 & $68.3 \pm 11.3^{*}$ \\
\hline \multicolumn{9}{|c|}{ TESTOSTERONE } \\
\hline Sham & 9 & $19.1 \pm 8.6$ & 10 & $103.4 \pm 14.0$ & 10 & $285.8 \pm 20.8$ & 10 & $76.5 \pm 20.8$ \\
\hline R-OVARY & 10 & $13.3 \pm 3.6$ & 10 & $128.2 \pm 13.7$ & 10 & $177.3 \pm 24.7^{*}$ & 8 & $26.7 \pm 8.9^{*}$ \\
\hline L-OVARY & 9 & $36.5 \pm 15.4$ & 9 & $77.8 \pm 14.6$ & 8 & $225.8 \pm 15.4$ & 10 & $68.5 \pm 11.8$ \\
\hline \multicolumn{9}{|c|}{ ESTRADIOL } \\
\hline Sham & 9 & $46.6 \pm 5.6$ & 10 & $38.6 \pm 2.8$ & 10 & $149.7 \pm 11.3$ & 10 & $30.2 \pm 2.6$ \\
\hline R-OVARY & 10 & $25.7 \pm 4.2^{*}$ & 10 & $31.0 \pm 2.9$ & 10 & $120.4 \pm 12.4$ & 8 & $31.2 \pm 2.9$ \\
\hline L-OVARY & 9 & $36.8 \pm 4.2$ & 9 & $35.5 \pm 1.3$ & 8 & $71.1 \pm 10.9^{* \&}$ & 10 & $26.4 \pm 2.0$ \\
\hline
\end{tabular}

Performed at $13.00 \mathrm{~h}$ of diestrus 1, diestrus 2, proestrus or estrus, sacrificed one hour after treatment.

${ }^{*} p<0.05$ vs. Control (ANOVA followed by Tukey's test); ${ }^{\&} p<0.05$ vs. R-Ovary (ANOVA followed by Tukey's test).

\section{Effects of Sectioning the SON in rats with ULO Effects on $\mathrm{P} 4$ serum levels}

Sectioning the right SON of animals with left ULO (right ovary in situ) on $\mathrm{P}$ or $\mathrm{E}$ resulted in higher $\mathrm{P} 4$ serum levels than in rats with left ULO (Figure 4A). In rats with right ULO (left ovary in situ) treatment, sectioning the left SON on P resulted in higher P4 levels (Figure 4B).

Effects on $T$ serum levels

In rats with left ULO (right ovary in situ) treatment, sectioning the right SON on D1 resulted in lower $\mathrm{T}$ levels than in ULO treated rats; while the same treatment performed on $\mathrm{E}$ resulted in higher $\mathrm{T}$ levels (Figure $5 \mathrm{~A})$. On D1 or P, sectioning the left SON to ULO rats resulted in lower $\mathrm{T}$ levels than in rats with the left ovary in situ, while the same treatment performed on D2 resulted in higher $\mathrm{T}$ levels than in ULO rats (Figure 5B).

\begin{tabular}{|c|c|c|c|c|}
\hline Treatment & Diestrus 1 & Diestrus 2 & Proestrus & Estrus \\
\hline \multicolumn{5}{|c|}{ Progesterone } \\
\hline Left ULO & $=$ & $=$ & $=$ & $=$ \\
\hline Right ULO & L & $=$ & $=$ & $\widehat{T \Gamma}$ \\
\hline \multicolumn{5}{|c|}{ Testosterone } \\
\hline Left ULO & $=$ & $=$ & 7 & $\Pi$ \\
\hline Right ULO & $=$ & $=$ & $=$ & $=$ \\
\hline \multicolumn{5}{|c|}{ Estradiol } \\
\hline Left ULO & $\Omega$ & $=$ & $=$ & $=$ \\
\hline Right ULO & $=$ & $=$ & $\square$ & $=$ \\
\hline $\begin{array}{l}=: \text { No difference in } \\
\text { Figure } \mathbf{2} \text { Summ } \\
\text { serum compared } \\
\text { surgery treatment. }\end{array}$ & $\begin{array}{l}\text { one concentra } \\
\text { f ULO tre } \\
\text { mone conc }\end{array}$ & $\begin{array}{l}\text { ment effe } \\
\text { mentions in }\end{array}$ & $\begin{array}{l}\text { ts. } P 4, T \text { at } \\
\text { nimals with }\end{array}$ & $\begin{array}{l}\text { ad } E \text { in } \\
\text { sham- }\end{array}$ \\
\hline
\end{tabular}

\section{Effects on E2 serum levels}

Sectioning the right SON of rats with left-ULO (right ovary in situ) on D1 or D2 resulted in higher E2 levels; while the same treatment on $\mathrm{P}$ resulted in lower E2 levels (Figure 6A). On the other, sectioning the left SON of rats with right-ULO (left ovary in situ) on D1 or D2 resulted in higher E2 levels than in rats with ULO (Figure 6B).

Comparative effects of unilaterally sectioning the SON of rats with both ovaries and ULO rats (figure 7)

Effects on P4 serum levels

In rats treated on D1 or E, P4 levels were higher in rats with $\mathrm{ULO}+$ sectioning the right SON than in rats with both ovaries and sectioning of the right SON treatment. Rats treated on D2 had an inverse response.

\section{Effects on $T$ serum levels}

In rats treated with $\mathrm{ULO}$ + sectioning the SON on D1, $\mathrm{T}$ levels were lower than in rats with both ovaries and sectioning of the SON (right or left) treatment. An inverse result occurred in rats treated on D2. Rats treated with $\mathrm{ULO}+$ sectioning the left SON on P had lower $\mathrm{T}$ levels than rats with both ovaries and sectioning of the left SON. In rats treated on E, rats with $\mathrm{ULO}+$ sectioning the right $\mathrm{SON}$ had lower $\mathrm{T}$ levels than rats with both ovaries and section of the right SON.

\section{Effects on E2 serum levels}

Rats with ULO + sectioning the right ovary treatment on D2, had higher E2 levels than rats with both ovaries and section of the right or left SON. Rats with ULO + sectioning the SON on P had lower E2 levels than rats with both ovaries and section of the right or left SON.

Figure 8 shows a summary of the effects of sectioning the SON to ULO rats on P4, T and E serum levels. Results were compared to the respective ULO treatment group. 
Table 3 Mean \pm SEM of progesterone $(\mathrm{ng} / \mathrm{ml})$, testosterone and estradiol $(\mathrm{pg} / \mathrm{ml})$ serum levels in rats with unilateral sectioning of the SON

\begin{tabular}{|c|c|c|c|c|c|c|c|c|}
\hline GROUP & $\mathrm{N}$ & D1 & $\mathrm{N}$ & D2 & $\mathrm{N}$ & $\mathbf{P}$ & $\mathrm{N}$ & 0 \\
\hline \multicolumn{9}{|c|}{ PROGESTERONE } \\
\hline Sham & 9 & $63.5 \pm 11.1$ & 10 & $103.4 \pm 14.0$ & 10 & $149.7 \pm 11.3$ & 10 & $26.3 \pm 1.1$ \\
\hline R-SON & 10 & $36.3 \pm 2.2^{*}$ & 8 & $115.1 \pm 15.7$ & 9 & $122.9 \pm 12.1$ & 8 & $40.2 \pm 4.1^{*}$ \\
\hline L-SON & 10 & $51.7 \pm 11.0$ & 8 & $62.2 \pm 13.8^{*} \#$ & 7 & $119.1 \pm 11.2$ & 8 & $71.2 \pm 6.7^{*} \#$ \\
\hline \multicolumn{9}{|c|}{ TESTOSTERONE } \\
\hline Sham & 9 & $19.1 \pm 8.6$ & 9 & $103.4 \pm 14.0$ & 10 & $285.8 \pm 28.0$ & 10 & $76.5 \pm 20.8$ \\
\hline R-SON & 10 & $20.3 \pm 1.9$ & 10 & $115.1 \pm 15.7$ & 9 & $194.7 \pm 22.1^{*}$ & 8 & $111.3 \pm 30.1$ \\
\hline L-SON & 10 & $51.0 \pm 8.4^{*}$ & 10 & $62.2 \pm 13.8^{*} \#$ & 7 & $306.2 \pm 22.2 \#$ & 8 & $56.7 \pm 10.9$ \\
\hline \multicolumn{9}{|c|}{ ESTRADIOL } \\
\hline Sham & 9 & $46.6 \pm 5.6$ & 9 & $38.6 \pm 2.8$ & 10 & $149.7 \pm 11.3$ & 10 & $30.2 \pm 2.6$ \\
\hline R-SON & 10 & $40.9 \pm 4.5$ & 10 & $42.7 \pm 5.7$ & 9 & $122.9 \pm 12.1$ & 8 & $48.9 \pm 5.9$ \\
\hline L-SON & 10 & $43.1 \pm 5.9$ & 10 & $49.5 \pm 3.2$ & 7 & $119.1 \pm 11.2$ & 8 & $62.0 \pm 12.1$ \\
\hline
\end{tabular}

Performed at $13.00 \mathrm{~h}$ of diestrus 1, diestrus 2, proestrus or estrus, sacrificed one hour after treatment.

* $\mathrm{p}<0.05$ vs. Control: \# $\mathrm{p}<0.05$ vs. R-SON (ANOVA followed by Tukey's test].

\section{Discussion}

The results presented herein support the hypotheses that secretion of ovarian steroid hormones is asymmetric and depend on the neural information arriving to the ovaries through the SON.

The results also support the hypothesis that the secretion of steroid hormones levels varies through the estrous cycle. The results suggest that the acute extirpation of one ovary modifies the mechanisms regulating hormone secretion and that these modifications depend on the extirpated ovary and the day of the cycle when surgery is performed.

Kawakami et al., [43,44] showed that electric stimulation of the ventromedial hypothalamus and of the medio-basal prechiasmathic area in hypophysectomized and adrenalectomized rats provoked the release of P4

\begin{tabular}{|c|c|c|c|c|}
\hline Treatment & Diestrus 1 & Diestrus 2 & Proestrus & Estrus \\
\hline \multicolumn{5}{|c|}{ Results are compared to sham surgery treatment results } \\
\hline \multicolumn{5}{|c|}{ Progesterone } \\
\hline Sectioning the right SON & $=$ & $=$ & $=$ & \\
\hline Sectioning the left SON & $\sqrt{-1}$ & ] & $=$ & $\widehat{T \Gamma}$ \\
\hline \multicolumn{5}{|c|}{ Testosterone } \\
\hline Sectioning the right SON & $=$ & $=$ & $\widehat{T \Gamma}$ & $=$ \\
\hline Sectioning the left SON & $\widehat{T \Gamma}$ & $\Omega$ & $=$ & $=$ \\
\hline \multicolumn{5}{|c|}{ Estradiol } \\
\hline Sectioning the right SON & $=$ & $=$ & $=$ & $=$ \\
\hline Sectioning the left SON & $=$ & $=$ & $=$ & $=$ \\
\hline \multicolumn{5}{|c|}{ Lower than sham surgery group. } \\
\hline \multicolumn{5}{|l|}{ : Higher than sham sur } \\
\hline $\begin{array}{l}3 \text { Summary of the } \\
\text { E serum levels. }\end{array}$ & effects of & ctionin & he SOI & on P4, \\
\hline
\end{tabular}

and E2 with no modifications in the levels of gonadotropins, or ovarian blood flow, and GnRH [45] suggesting a direct neural control of the ovarian steroidogenesis. In the pre-pubertal rat the differences on $\mathrm{P} 4, \mathrm{~T}$ and $\mathrm{E} 2$ levels induced by right- or left-ULO did not correlate with changes in FSH or LH concentrations, suggesting that the acute effects of unilateral ovariectomy on P4, T and E2 secretion by the ovaries does not depend on gonadotropin signals [46].

Noradrenaline and vasoactive intestinal peptide (VIP) stimulate the ovarian release of $\mathrm{P} 4$, while $\mathrm{GnRH}$ and gamma aminobutyric acid (GABA) play an inhibitory role. Some of these neurotransmitters are also present in the SON and the coeliac ganglion [39]. In vitro studies by Garraza et al. [29] show that NPY, VIP or SP applied directly on the ovaries obtained from rats on D1 inhibit the secretion of $\mathrm{P} 4$, while the same treatment on ovaries from rats on D2 stimulates P4 secretion. The participation of the ovaries and adrenals in maintaining normal P4 levels vary during the estrous cycle. There is evidence indicating the ovaries release more P4 on D1 than the adrenals; while on D2, P and E, the main source of P4 are the adrenals [47]. In the present study, by comparison with untouched control rats, the increase of P4 levels in sham-surgery rats treated on D1 or D2 was higher than those observed in ether-anaesthetised rats $(164 \%$ vs. $20.6 \%$; $237 \%$ vs. $66.2 \%)$ [34,35] suggesting that the abdominal skin stimulation play a stimulatory role on P4 release during D1 and D2. A similar effect was observed with $\mathrm{T}$ levels in sham-surgery rats treated on D2 or E. The neural connections between the abdominal skin and the ovaries proposed by Uchida et al [20] would be the neural path used.

Present results show that removing the right ovary (left ovary in situ) on D1 resulted in lower P4 level, but removing the left ovary (right ovary in situ) results in 


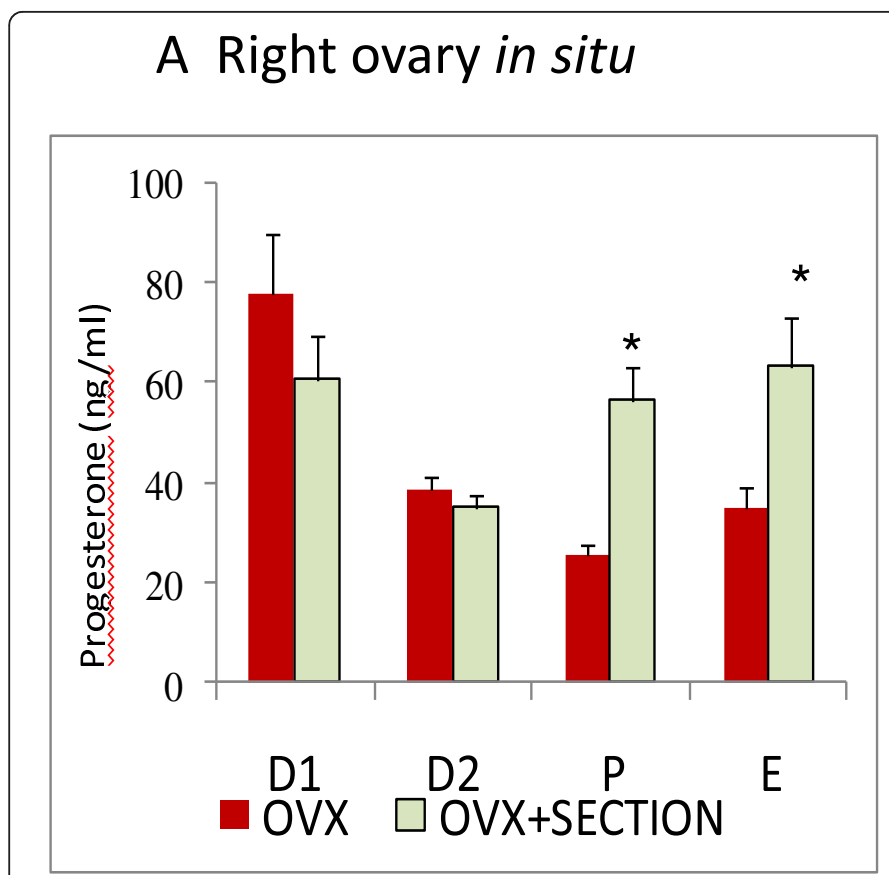

\section{B Left ovary in situ}

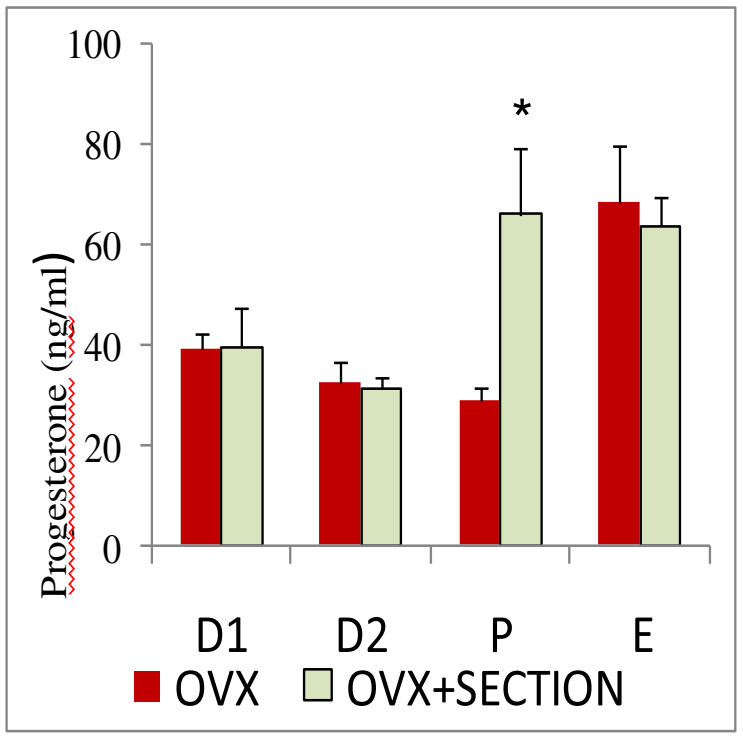

Figure 4 Progesterone serum levels. Means \pm SEM of progesterone serum levels $(\mathrm{ng} / \mathrm{ml})$ in rats with unilateral ovariectomy $(O V X)$ and unilateral ovariectomy followed the section of the superior ovarian nerve (OVX + SECTION) of the in situ ovary ( A - right in situ ovary; B - left in situ ovary). ${ }^{*} p<0.05$ vs. OVX (Student's test).

hormone levels similar to animals with sham surgery treatment. The results suggest that the increase in $\mathrm{P} 4$ levels observed in animals with sham surgery treatment depend on the secretion activity by the right ovary.
Since sectioning the left SON on D1 or D2 resulted in lower P4 levels than in sham surgery treated rats, we propose that the neural reflex elicited by the sham surgery arrives to the left ovary through the left SON.

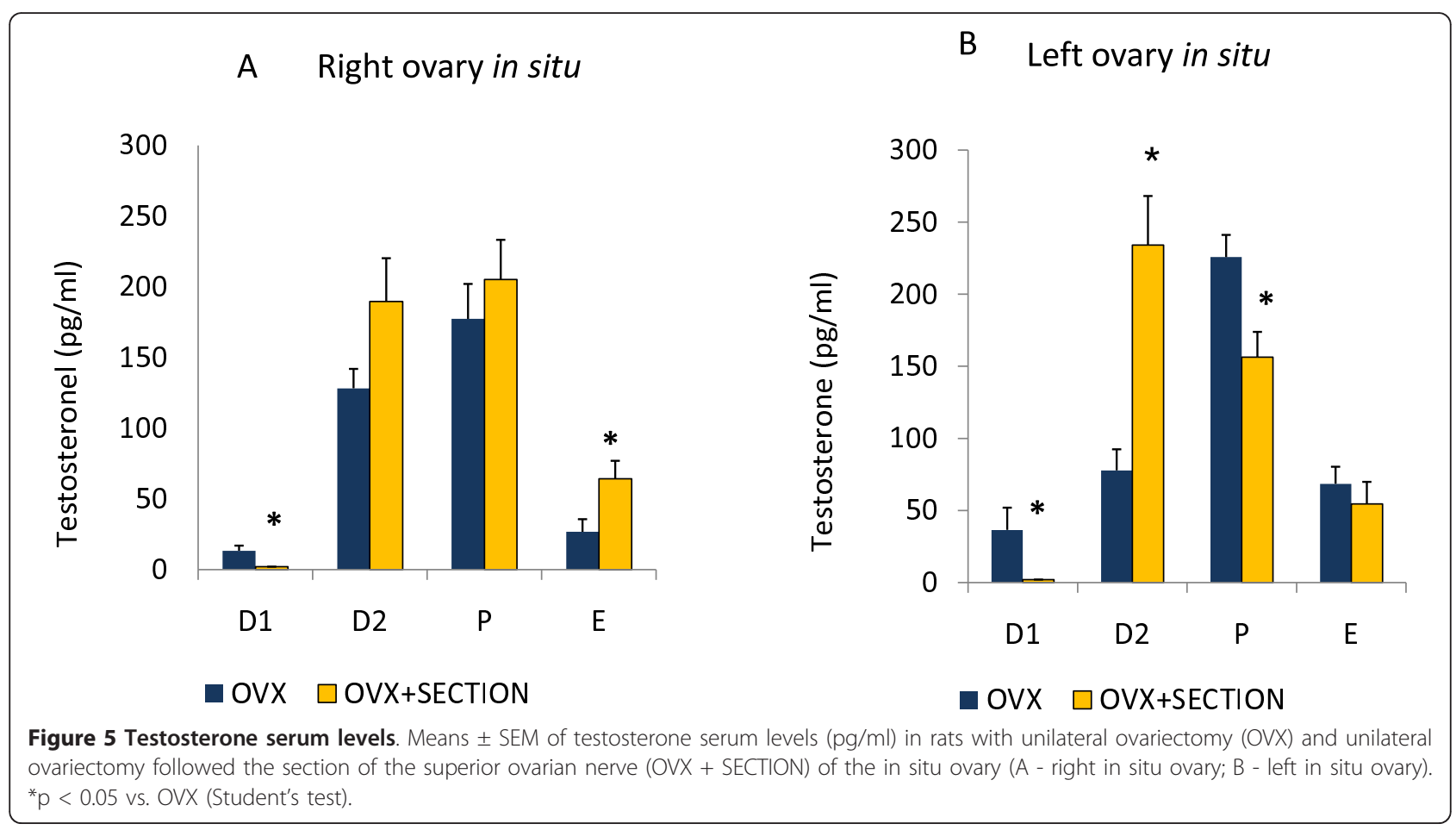




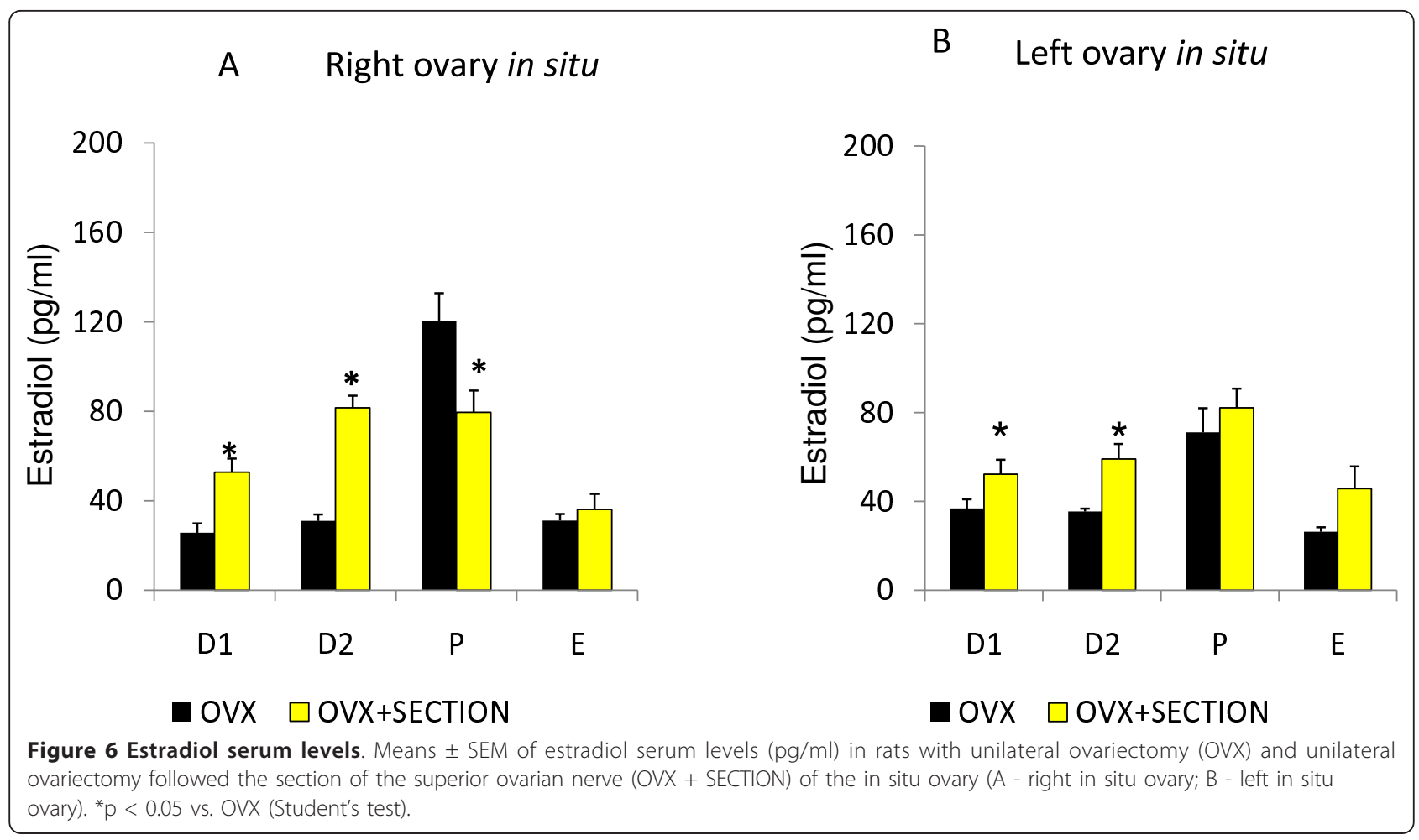

The decrease in P4 levels could be explained by the decrease in ovarian NA and VIP quantities, since the unilateral or bilateral sectioning of the SON results in an acute decrease in NA levels $[17,33]$, and both neurotransmitters stimulate ovarian P4 secretion [48].

As indicated by the present results, rats with rightULO (left ovary in situ) on E showed higher P4 levels than animals in the sham-surgery treatment group. We suppose that the increase in P4 secretion originates in the adrenals. Since the noradrenergic nerves arriving to the ovaries and the adrenals originate at the CSMG [49], it is possible that some kind of neural information arising from the left ovary is carried to the CSMG resulting in the stimulation of the nerves innervating the adrenals. Since sectioning the left or right SON also resulted in higher P4 levels, we suppose that on the day of $\mathrm{E}$ the neural information carried by both SONs regulates P4 secretion in an inhibitory way, which does not include NA and VIP as neurotransmitters.

Removing the left ovary modified the way P4 secretion is regulated by the right ovary; since sectioning the right SON on $\mathrm{P}$ or $\mathrm{E}$ resulted in higher $\mathrm{P} 4$ levels than in ULO rats with the right ovary in situ. A similar effect occurred in rats with the left ovary in situ with section of the left SON at P.

According to Odell and Parker [50], the major adrenal androgens are dehydroepiandrosterone (DHEA), dehydroepiandrosterone sulphate (DHEAS), and A4; which are converted into androgen and estrogen by steroidogenic enzymes in the peripheral tissues [51]. In the rat, $\mathrm{T}$ secretion by the adrenals is limited [52]; and thus, the changes in hormone levels observed in response to ULO or denervation must be explained by modifications in the ovarian capacity to secrete $\mathrm{T}$. In rats with ULO treatment the SON plays a stimulatory role in secreting $\mathrm{T}$ by the left ovary, while for the right ovary, the SON plays a stimulatory on D1 and an inhibitory role on E. Such difference may result from changes in the sensitivity of the ovary to the effects of LH and/or by the stimulation of P450 aromatase activity. On D1, ULO rats with a denervated ovary had lower $\mathrm{T}$ levels and higher E2 levels than rats with just ULO treatment.

At the day of estrus, the right SON plays an inhibitory role in ovarian E2 secretion [40]. ULO acute effects on E2 levels were observed on D1 for the right ovary and on $\mathrm{P}$ for the left ovary. For the right ovary the changes in E2 secretion depend on the innervations provided by the SON, but it does not for the left ovary, suggesting that the left and right ovaries have different kinds of regulation.

In vitro studies show that the ovaries'ability to secrete hormones changes with the presence or absence of a diverse group of neurotransmitters [21,53-55]. Then, the acute effects of ULO or sectioning the SON seem to influence the activity and/or the expression of enzymes participating in the synthesis of steroid hormones produced by the ovaries. 


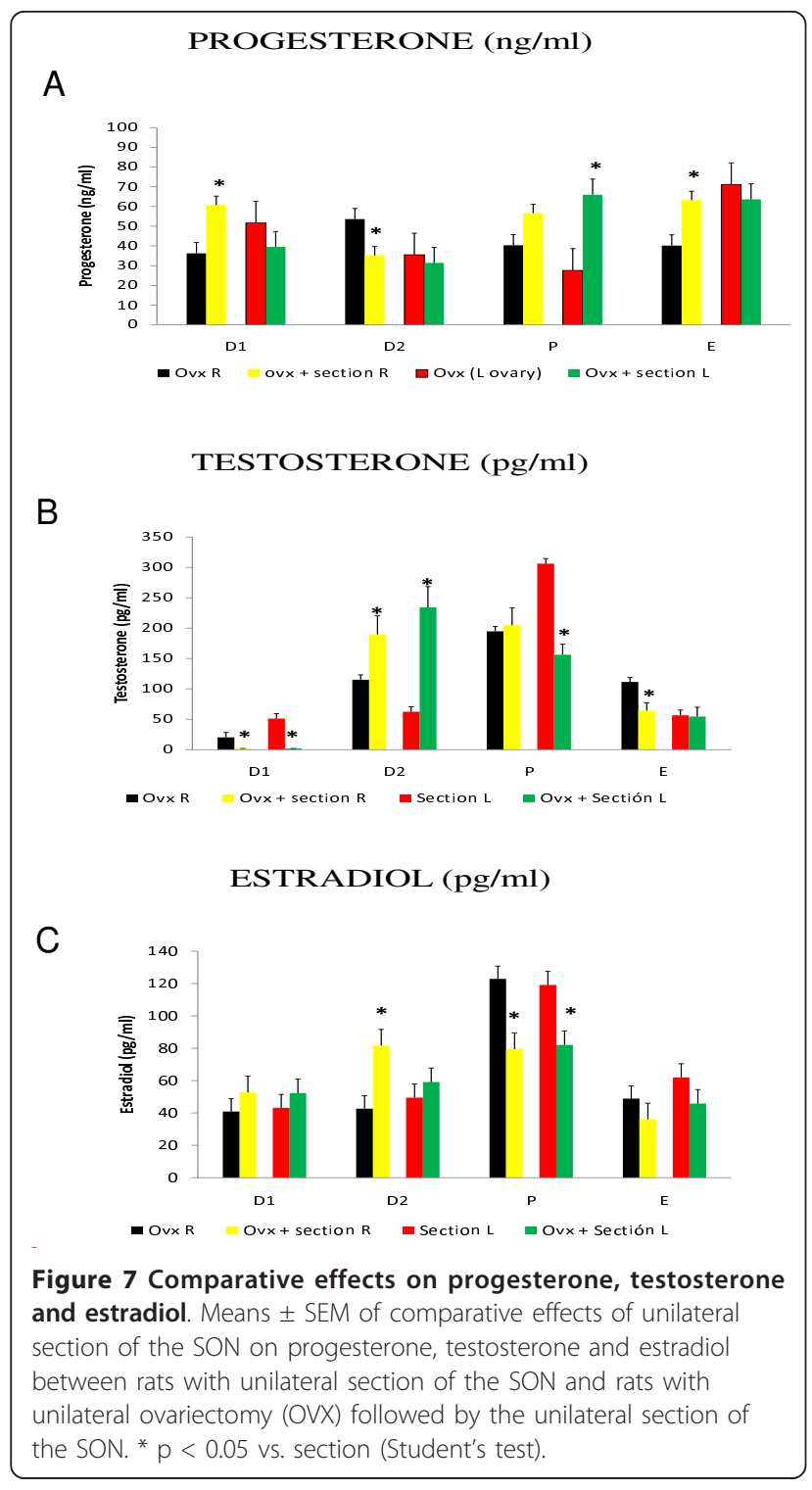

In ULO rats, sectioning the SON of the in situ ovary results in a different response than that observed in animals with both ovaries; suggesting that the effects of ULO result from the modifications in ovarian hormone levels, and the alterations on the neural information arising from the extirpated organ [1].

The variations in the asymmetrical performance by the right and left ovaries during the estrous cycle could be related to changes in the neural information received by the ovaries from the CSMG. Morán et al [56] showed that the neural connections between the CSMGs and the right and left ovaries show a mirror-image vary along the estrous cycle, and that the left ovary, but not the right one, has connections with both CSMGs. Furthermore, the SON is the main neural pathway connecting the ovaries to the CSMG [48].

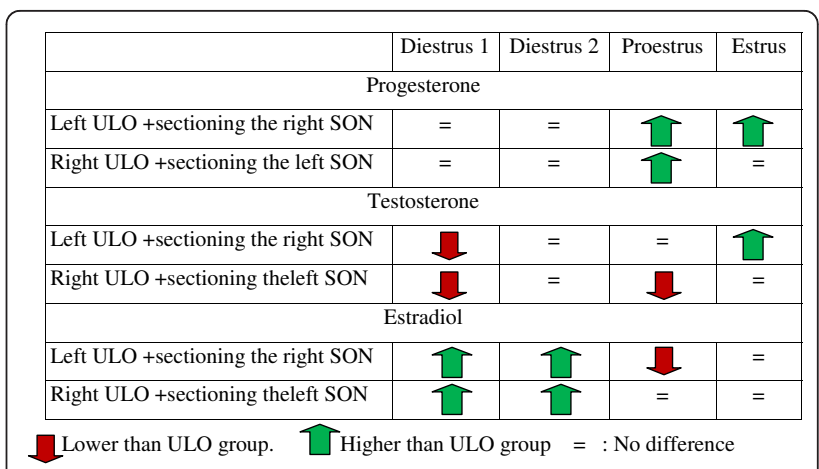

Figure 8 Summary of the effects of sectioning the SON to ULO rats on P4, T and E serum levels. Results were compared to the respective ULO treatment group.

Mortality for neurological or mental diseases is higher in women who underwent bilateral oophorectomy before age 45 years compared with referent women and it is not attenuated by estrogen treatment from the time of oophorectomy [57].

In women of reproductive age, the most common endocrinopathy is polycystic ovary syndrome (PCOS). There is evidence that PCOS is associated with increased sympathetic nerve activity, since repeated low-frequency electroacupuncture treatment induced regular ovulation in women with PCOS [58], inhibited hyperactivity in the sympathetic nervous system [59] and improved hyperandrogenism $[58,60]$. Bilateral sectioning of the $\mathrm{SON}$ to rats with PCOS, induced by estradiol valerate, restored ovulation [61], while unilateral sectioning of the SON restored ovulation in the innervated ovary [62]. The neural reflexes induced from the abdominal skin to the ovaries affect ovarian blood flow and SON activity [20] and low-frecuency electro-acupuncture treatment is achieved by acting on the wall of the abdomen. Then, it is possible that their effects could be related with changes in the SON activity. Such possibility is based in present results (acute changes in P4, $\mathrm{T}$ and E2 levels induced by ovarian denervation and elimination of one of the neural communication between the ovary and the CNS) and Kagitani et al. [40] results showing that SON stimulation results in a decrease in E2 secretion

Taken together, present and previous results indicate that the mechanism regulating steroid hormones secretion by the ovaries is different for each hormone and for each ovary. Endocrine signals originate from, and arrive to, the ovaries; the ovaries receive and send neural information that is processed in the CNS and participate in regulating the secretion of gonadotropins related to the regulation of ovarian functions.

\section{Acknowledgements}

We thank MSc Alvaro Domínguez-González for assistance in English revision. DGAPA-UNAM Grants IN 200405 and IN209508 supported this research. 


\section{Authors' contributions}

AF and RD conceived and designed the study. JV, AIG, FDM and PME performed the surgeries and hormone measurements. MEC participated in the analysis and discussion of the results. RD prepared the initial draft of the manuscript. All co-authors provided inputs during final manuscript preparation. All authors read and approved the final manuscript.

\section{Competing interests}

The authors declare that they have no competing interests.

Received: 27 August 2010 Accepted: 18 March 2011 Published: 18 March 2011

\section{References}

1. Domínguez R, Morales L, Cruz ME: Ovarian asymmetry. Ann Rev Biomed Sci 2003, 5:95-104.

2. Chávez R, Cruz ME, Domínguez R: Differences in the ovulation rate of the right or left ovary in unilaterally ovariectomized rats: effect of ipsi- and contralateral vagus nerves on the remaining ovary. J Endocrinol 1987, 113:397-401.

3. Chávez R, Sánchez S, Ulloa-Aguirre A, Domínguez R: Effects on estrous cyclicity and ovulation of unilateral section of the vagus nerve performed on different days of the estrous cycle in the rat. J Endocrinol 1989, 123:441-444

4. Chávez R, Carrizosa L, Domínguez R: Effects of superior ovarian nerve section on spontaneous and induced ovulation in the adult rat. Med Sci Res 1991, 19:41-42

5. Morales L, Chávez R, Ayala ME, Domínguez R: Effects of unilateral or bilateral superior ovarian nerve section in prepubertal rats on the ovulatory response to gonadotrophin administration. J Endocrinol 1998, 158:213-219.

6. De Bortoli MA, Garraza MH, Aguado LI: Adrenergic intracerebroventricular stimulation affects progesterone concentration in the ovarian vein of the rat: participation of the superior ovarian nerve. J Endocrinol 1998, 159:61-68.

7. De Bortoli MA, Garraza MH, Aguado LI: Involvement of betaadrenoceptors in a central regulation of the ovarian progesterone release in rats. Neuro Endocrinol Lett 2002, 23:27-31.

8. Domínguez R, Cruz ME, Chávez R: Differences in the ovulatory ability between the right and left ovary are related to ovarian innervation. In Growth factors and the ovary. Edited by: Hirshfield AN. New York: Plenum Press; 1989:321-325.

9. Burden HW: Ovarian innervation. In The vertebrate ovary. Edited by: Jones RE. New York: Plenum Press; 1978:615-638.

10. Klein $\mathrm{CM}$, Burden HW: Anatomical localization of afferent and postganglionic sympathetic neurons innervating the rat ovary. Neurosci Lett 1988, 85:217-222.

11. Lawrence IE, Burden HW: The origin of the extrinsic adrenergic innervation to the rat ovary. Anat Rec 1980, 196:51-59.

12. Gerendai I, Toth IE, Boldogkoi Z, Medveczky I, Halász B: CNS structures presumably involved in vagal control of ovarian function. J Auton Nerv Syst 2000, 80:40-45.

13. Ojeda SR, Costa ME, Katz KH, Hersh LB: Evidence for the existence of substance $\mathrm{P}$ in the prepubertal rat ovary. I. Biochemical and physiologic studies. Biol Reprod 1985, 33:286-295.

14. Ahmed CE, Dees WL, Ojeda SR: The immature rat ovary is innervated by vasoactive intestinal peptide (VIP]-containing fibers and responds to VIP with steroid secretion. Endocrinology 1986, 118:1682-1689.

15. McNeill DL, Burden HW: Peripheral pathways for neuropeptide $Y$ - and cholecystokinin-8-immunoreactive nerves innervating the rat ovary. Neurosci Lett 1987, 80:27-32.

16. McNeill DL, Burden HW: Neuropeptides in sensory perikarya projecting to the rat ovary. Am J Anat 1987, 179:269-276.

17. Dees WL, Ahmed CE, Ojeda SR: Substance P and vasoactive intestinal peptide-containing fibers reach the ovary by independent routes. Endocrinology 1986, 119:638-641.

18. Klein $C M$, Burden HW: Substance $P$ and vasoactive intestinal polypeptide (VIP) immunoreactive nerve fibers in relation to ovarian postganglionic perikarya in para- and prevertebral ganglia: evidence from combined retrograde tracing and immunocytochemistry. Cell Tissue Res 1988, 252:403-418
19. Barria A, Leyton V, Ojeda SR, Lara HE: Ovarian steroidal response to gonadotropins and beta-adrenergic stimulation is enhanced in polycystic ovary syndrome: role of sympathetic innervation. Endocrinology 1993, 133:2696-2703.

20. Uchida S, Kagitani F, Hotta H, Hanada T, Aikawa Y: Cutaneous mechanical stimulation regulates ovarian blood flow via activation of spinal and supraspinal reflex pathways in anesthetized rats. Jpn J Physiol 2005, 55:265-277.

21. Stener-Victorin E, Fujisawa S, Kurosawa M: Ovarian blood flow responses to electroacupuncture stimulation depend on estrous cycle and on site and frequency of stimulation in anesthetized rats. J Appl Physiol 2006, 101:84-91.

22. Niswender GD, Reimers TJ, Diekman MA, Nett TM: Blood flow: a mediator of ovarian function. Biol Reprod 1976, 14:64-81.

23. Varga B, Greenwald GS: Cyclic changes in utero-ovarian blood flow and ovarian hormone secretion in the hamster: effects of adrenocorticotropin, luteinizing hormone, and follicle-stimulating hormone. Endocrinology 1979, 104:1525-1531.

24. Garris DR, Foreman D: Follicular growth and atresia during the last half of the luteal phase of the guinea pig estrous cycle: relation to serum progesterone and estradiol levels and utero-ovarian blood flow. Endocrinology 1984, 115:73-77.

25. Sweeney TE, Bagher P, Bailey J, Cherra SJ, Grisafi FN, Pauli EM, Riley K, Soares S: Intravascular pressure and diameter profile of the utero-ovarian resistance artery network: estrous cycle-dependent modulation of resistance artery tone. Am J Physiol Heart Circ Physiol 2007, 293: H2937-2944.

26. Forsman AD, McCormack JT: Microcorrosion casts of hamster luteal and follicular vasculature throughout the estrous cycle. Anat Rec 1992, 233:515-520

27. Aguado LI: Role of the central and peripheral nervous system in the ovarian function. Microsc Res Tech 2002, 59:462-473.

28. Chávez R, Morales L, Gonzalez ME, Domínguez R: Ovarian norepinephrine content in prepubertal rats with superior ovarian nerve section. Temporally studies. Med Sci Res 1994, 22:789-790.

29. Garraza MH, Aguado LI, De Bortoli MA: In vitro effect of neuropeptides on ovary or celiac ganglion affects the release of progesterone from ovaries in the rat. Med Sci Monit 2004, 10:440-446.

30. Casais M, Delgado SM, Vallcaneras S, Sosa Z, Rastrilla AM: Nitric oxide in prepubertal rat ovary contribution of the ganglionic nitric oxide synthase system via superior ovarian nerve. Neuro Endocrinol Lett 2007, 28:39-44.

31. Snyder GD, Holmes RW, Bates JN, Van Voorhis BJ: Nitric oxide inhibits aromatase activity: mechanisms of action. J Steroid Biochem Mol Biol 1996, 58:63-69.

32. Burden HW, Lawrence IE Jr: The effects of denervation on the localization of delta5-3beta-hydroxysteroid dehydrogenase activity in the rat ovary during pregnancy. Acta Anat (Basel) 1977, 97:286-290.

33. Jana B, Dzienis A, Wojtkiewicz J, Kaczmarek M, Majewski M: Surgical denervation of porcine ovaries during the middle luteal phase of the oestrous cycle changes their morphology and steroidogenic activity. Acta Vet Hung 2007, 55:107-122.

34. Barco Al, Flores A, Chavira R, Damian-Matsumura P, Domínguez R, Cruz ME: Asymmetric effects of acute hemiovariectomy on steroid hormone secretion by the in situ ovary. Endocrine 2003, 21:209-215.

35. Flores A, Meléndez G, Palafox MT, Rodríguez JO, Barco Al, Chavira R, Domínguez R, Cruz ME: The participation of the cholinergic system in regulating progesterone secretion through the ovarian-adrenal crosstalk varies along the estrous cycle. Endocrine 2005, 28:145-152.

36. Flores A, Rodríguez JO, Palafox MT, Meléndez G, Barco Al, Chavira R, Cruz ME, Domínguez $R$ : The acute asymmetric effects of hemiovariectomy on testosterone secretion vary along the estrous cycle. Participation of the cholinergic system. Reprod Biol Endocrinol 2006, 4:11.

37. Cruz ME, Flores A, Palafox MT, Meléndez G, Rodríguez JO, Chavira R, Domínguez $R$ : The role of the muscarinic system in regulating estradiol secretion varies during the estrous cycle: the hemiovariectomized rat model. Reprod Biol Endocrinol 2006, 4:43.

38. Tóth IE, Wiesel O, Boldogkói Z, Bálint K, Tapaszti Z, Gerendai I: Predominant innervation of the left ovary. Microsc Res Tech 2007, 70:710-718. 
39. Chávez R, Domínguez R: Participation of the superior ovarian nerve in the regulation of compensatory ovarian hypertrophy: the effects of its section performed on each day of the oestrous cycle. J Endocrinol 1994 140:197-201.

40. Kagitani F, Uchida S, Hotta H: Effects of electrical stimulation of the superior ovarian nerve and the ovarian plexus nerve on the ovarian estradiol secretion rate in rats. J Physio/ Sci 2008, 58:133-138.

41. Trujillo A, Morales L, Dominguez R, Vindrola O: Effects of sensorial denervation on the ovarian functions in the adult rat. Program No. 734.14 Neuroscience Meeting Planner. San Diego, Ca; 2001.

42. Trujillo A, Morales L, Vargas X, Alba L, Domínguez R: Effects of capsaicin treatment on the regulation of ovarian compensatory hypertrophy and compensatory ovulation. Endocrine 2004, 25:155-162.

43. Kawakami M, Kubo K, Uemura T, Nagase M: Evidence for the existence of extra-hypophyseal neural mechanisms controlling ovarian steroid secretion. J Steroid Biochem 1979, 11:1001-1005.

44. Kawakami M, Kubo K, Uemura T, Nagase M, Hayashy R: Involvement of ovarian innervation on steroid secretion. Endocrinology 1981, 109:136-145.

45. Chiappas SA, Fink G, Sherwood MM: Immunoreactive luteinizing hormone-releasing factor (LHRF) in pituitary stalk plasma from female rats: effect of stimulating diencephalon, hippocampus and amygdala. J Physiol 1977, 267:625-640.

46. Ramírez DA, Vieyra E, Morales L, Dominguez R: The acute effects of unilateral ovariectomy to prepubertal rats on gonadotropin and hormone ovarian secretion are asymmetric. Program No. 81.3 Washington, DC: Society for Neuroscience; 2008, Online.

47. Flores A, Gallegos Al, Velasco J, Mendoza FD, Montiel C, Everardo P, Cruz ME, Domínguez R: The acute effects of bilateral ovariectomy or adrenalectomy on progesterone, testosterone and estradiol serum levels depend on the surgical approach and the day of the estrous cycle when they are performed. Reprod Biol Endocrinol 2008, 6:48.

48. Casais M, Sosa ZY, Rastrilla AM, Aguado LI: Coeliac ganglion adrenergic activity modifies ovarian progesterone during pregnancy: its interrelationship with LH. J Endocrinol 2001, 170:575-584.

49. Morán C, Franco A, Morán JL, Handal A, Morales L, Domínguez R: Neural activity between ovaries and the prevertebral celiac-superior mesenteric ganglia varies during the estrous cycle of the rat. Endocrine 2005, 2:147-152

50. Odell WD, Parker LN: Control of adrenal androgen production. Endocrine Res 1984, 10:617-630

51. Labrie F, Luu-The V, Labrie C, Simard J: DHEA and its transformation into androgens and estrogens in peripheral target tissues: intracrinology. Front Neuroendocrinol 2001, 22:185-212.

52. Stahl F, Gotz F, Dorner G: The influence of fetal adrenals on the androgen levels during brain differentiation in human subjects and rats. Exp Clin Endocrinol 1991, 98:131-139.

53. Aguado LI, Ojeda SR: Prepuberal ovarian function is finely regulated by direct adrenergic influences: role of noradrenergic innervation. Endocrinology 1984, 114:1845-1853.

54. Aguado LI, Ojeda SR: Ovarian adrenergic nerves play a role in maintaining preovulatory steroid secretion. Endocrinology 1984, 114:1944-1946.

55. Erdö $S L$, Varga $B$, Horvath E: Effect of local GABA administration on rat ovarian blood flow and on progesterone and estradiol secretion. Eur J Pharmacol 1985, 111:397-404.

56. Morán C, Zarate F, Morán JL, Handal A, Domínguez R: Lateralization of the connections of the ovary to the celiac ganglia in juvenile rats. Reprod Biol Endocrinol 2009, 7:50-58.

57. Rivera CM, Grossardt BR, Rhodes DJ, Rocca WA: Increased mortality for neurological and mental diseases following early bilateral oophorectomy. Neuroepidemiology 2009, 33:32-40.

58. Stener-Victorin $E$, Waldenström $U$, Tägnfors $U$, Lundeberg T, Lindstedt $G$, Janson PO: Effects of electro-acupuncture on anovulation in women with polycystic ovary syndrome. Acta Obstet Gynecol Scand 2000, 79:180-188.

59. Stener-Victorin $E_{\text {, Jedel }} E_{\text {, Janson } P O}$, Sverrisdottir $Y B$ : Low-frequency electroacupuncture and physical exercise decrease high muscle sympathetic nerve activity in polycystic ovary syndrome. Am J Physiol Regul Integr Comp Physiol 2009, 297:R387-395.

60. Jedel E, Labrie F, Odén A, Holm G, Nilsson L, Janson PO, Lind AK, Ohlsson C, Stener-Victorin E: Impact of electro-acupuncture and physical exercise on hyperandrogenism and oligo/amenorrhea in women with polycystic ovary syndrome: a randomized controlled trial. Am J Physiol Endocrinol Metab 2011, 300:E37-45.

61. Lara HE, Ferruz JL, Luza S, Bustamante DA, Borges Y, Ojeda SR: Activation of ovarian sympathetic nerves in polycystic ovary syndrome. Endocrinology 1993, 133:2690-2695.

62. Morales-Ledesma L, Linares R, Rosas G, Morán C, Chavira R, Cárdenas M, Domínguez R: Unilateral sectioning of the superior ovarian nerve of rats with polycystic ovarian syndrome restores ovulation in the innervated ovary. Reprod Biol Endocrinol 2010, 8:99.

doi:10.1186/1477-7827-9-34

Cite this article as: Flores et al: Acute effects of unilateral sectioning the superior ovarian nerve of rats with unilateral ovariectomy on ovarian hormones (progesterone, testosterone and estradiol) levels vary during the estrous cycle. Reproductive Biology and Endocrinology 2011 9:34.

\section{Submit your next manuscript to BioMed Central and take full advantage of:}

- Convenient online submission

- Thorough peer review

- No space constraints or color figure charges

- Immediate publication on acceptance

- Inclusion in PubMed, CAS, Scopus and Google Scholar

- Research which is freely available for redistribution 